American Journal of Pharmaceutical Education 2018; 82 (9) Article 6430.

\title{
RESEARCH
}

\section{Design and Delivery of Clinical Pharmacokinetics in Colleges and Schools of Pharmacy}

\author{
Gregory J. Hughes, PharmD, ${ }^{a}$ Ruby Lee, PharmD, ${ }^{b}$ Vassilia Sideras, PharmD ${ }^{c}$ \\ a St. John's University College of Pharmacy and Health Sciences, Queens, New York \\ ${ }^{\mathrm{b}}$ New York-Presbyterian/Weill Cornell Medical Center, New York, New York \\ ${ }^{c}$ Albany Medical Center, Albany, New York \\ Submitted March 28, 2017; accepted January 22, 2018; published November 2018.
}

Objective. To describe how clinical pharmacokinetics is being delivered across curricula in pharmacy programs, including the curricular position of clinical pharmacokinetic topics, topics currently taught, and instructional methods used in delivering the course content.

Methods. A survey was distributed to one representative faculty member from each pharmacy college who was most able to answer questions about their institution's delivery of clinical pharmacokinetic material.

Results. Responses were collected from 82 out of the 108 pharmacy colleges who participated in the study. Clinical pharmacokinetics was integrated within other courses through the curriculum in $41 \%$ of colleges and includes a substantial amount of math-based material. The most common instructional methods were lectures and practice with actual pharmacokinetic cases. The majority of the schools used examinations and quizzes to determine students' grades. Certain drugs remain popular (ie, aminoglycosides, vancomycin, digoxin) while others have fallen out of favor (ie, procainamide, phenytoin, theophylline). Various methods were used to deliver the material and assess student learning.

Conclusion. The delivery of clinical pharmacokinetic material has changed in the recent past across pharmacy colleges in the United States. Spreading clinical pharmacokinetics throughout the curriculum while maintaining the math-centric nature of the material has occurred. Clinical pharmacokinetics is a changing field and these results can be used to compare an institution's current content and delivery methods with other institutions. These aggregate results may be useful for schools that are redesigning their curriculum or are considering doing so.

Keywords: clinical pharmacokinetics, curriculum, course content

\section{INTRODUCTION}

Clinical pharmacokinetics (PK) is an increasingly important skill for graduating pharmacists. The 2016 Accreditation Council for Pharmacy Education (ACPE) standards indicate that education on kinetic principles is required in biochemistry, biopharmaceutics, and in clinical settings. ${ }^{1}$ As graduating pharmacists move into the workplace, they may find that there are various clinical patient care responsibilities that require the use of clinical PK. Formalized processes now exist in some institutions that permit pharmacists to perform dosing initiation and adjustments under an institutional protocol. Hospitals

Corresponding Author: Gregory J. Hughes, Department of Clinical Health Professions, St. John's University College of Pharmacy and Health Sciences, 8000 Utopia Pkwy., Queens, NY 11439. Tel: 718-990-8265. E-mail: hughesg@stjohns.edu may allow orders for certain medications to be written as "pharmacy to dose," enabling pharmacists to prescribe and make dosing decisions regarding drugs that require "therapeutic drug monitoring."

The most recent research on how pharmacy schools prepare students with these knowledge and abilities dates back to 2003 from Spruill and colleagues. ${ }^{3}$ This study surveyed instructors of clinical PK about the state of clinical PK instruction. Since 2003, the practice of clinical PK has continued to evolve and the Doctor of Pharmacy (PharmD) degree is now ubiquitously offered. Because many programs have likely altered their curricula and delivery of clinical PK, an update to the 2003 study is warranted.

The purpose of this study was to update the available knowledge on how clinical PK is being delivered across curricula in ACPE-accredited programs. The goals are to describe the curricular position of clinical PK topics, 


\section{American Journal of Pharmaceutical Education 2018; 82 (9) Article 6430.}

which topics are still being taught, and what instructional methods are used in delivering the course content.

\section{METHODS}

Deans and chairpersons of pharmacy practice departments at ACPE-accredited or candidate pharmacy colleges were individually contacted in July 2016 via phone and email and were asked to provide the clinical PK instructor in their respective institution who would best be able to answer a survey about clinical PK. A description of the intent of the survey and several sample survey questions were included in the request to increase the chances of reaching the single best person to complete the survey. These instructors were then individually contacted by email to briefly explain the purpose of the study and to obtain consent. Surveys were sent via an online survey tool to one consented instructor per pharmacy college. Reminders were sent weekly for roughly one month. The respective pharmacy colleges and respondents' names were kept anonymous throughout the survey. The answers were compiled and analyzed using descriptive statistics and a Chi-squared test was used for categorical data (Microsoft Excel 2010, Redmond, WA). The survey was organized into four categories and contained 20 questions in total. The survey used formatting and questions similar to the 2003 study by Spruill and colleagues so that comparisons could consistently be made. ${ }^{3}$

The first category contained 11 questions that addressed the curriculum. Questions were related to courses that institutions first teach to lay the basic principles of PK, whether PK was taught as a standalone course or integrated within other courses, and whether PK was required or an elective. This section also assessed the textbooks and case-based books used, the professional year taught, and the percentage breakdown of math versus non-math-based material. Additionally, instructors were surveyed to see if pharmacogenomics was taught as a standalone course. In the past several decades, interest in pharmacogenomics has been growing and it has been identified twice as a required element in the $2016 \mathrm{ACPE}$ standards. ${ }^{1}$ As both PK and pharmacogenomics have overlapping concepts and both address medications used in various therapeutic topics, one of the goals of this study was to identify pharmacogenomics' position as a standalone course versus its integration within other courses.

The second category addressed the course design, which contained five questions focusing on instructional and assessment methods. This section also included questions related to student expectations such as whether equations were provided or memorized for examinations and the type of calculator permitted during examinations. Instructors were also given the opportunity to briefly describe any recitation class structure.
The third category addressed the specific course content. Instructors were asked to identify from a list of 35 different units of instruction, which included medications, classes, dosing in certain disease states, dosing in certain populations, and specific mathematical models that were covered in their curriculum. Instructors were also asked if any unique teaching methods were used throughout the course such as writing a dosing policy, individual presentations, or online quizzes among others.

The last section allowed instructors to identify other teaching methods that were not previously mentioned and asked if they wanted to receive the preliminary results of the survey. A question on ACPE-accreditation status was also included.

\section{RESULTS}

Of the 136 pharmacy colleges contacted, 108 replied with the contact information of the person best suited to complete the survey. Of those, 82 recipients completed the survey, resulting in a $76 \%$ response rate. Ninety-four percent of responding institutions were ACPE-accredited and $6 \%$ were candidate status. Table 1 shows the survey results addressing the questions that pertain to the course curriculum, such as prerequisite courses, how PK is offered within the institution, textbooks or case-based books used, professional year taught, and the percentage breakdown of math- vs non-math-based material. Sixtysix percent of respondents taught a basic PK course prior to the clinical PK material. Fifty-nine percent responded that their clinical PK material was taught in standalone courses. Sixty-eight percent of schools delivered this content in the second professional year and 53\% in the third professional year, and the emphasis on mathematical calculations varied widely from $10 \%$ to $100 \%$. Three textbooks by Shargel, ${ }^{4}$ Winter, ${ }^{5}$ and Bauer, ${ }^{6}$ were used by $80 \%$ of the respondents and $40 \%$ of institutions also reported using an "other" textbook.

Table 2 is a compilation of survey questions that pertain to the course design, including instructional methods used in the course and assessments to determine students' grades. This table also includes information on whether students were required to memorize PK equations and the most complex type of calculator allowed on examinations. Respondents used examinations (98\%), quizzes (78\%), and individual assignments (56\%) to assess student learning. Class participation (32\%) and group assignments (38\%) were less common but still used to determine grades. For examinations, $84 \%$ of students were provided the PK equations rather than having to memorize them. They were restricted to using only scientific calculators in $88 \%$ of cases, rather than more 
American Journal of Pharmaceutical Education 2018; 82 (9) Article 6430.

Table 1. Curricular Position and Role of Clinical PK $(\mathrm{N}=82)$

Which courses does your institution first teach
to lay the basic principles that lead up to
applied/clinical PK course(s)?
Biopharmaceutics
Basic PK
Other
Is clinical or applied PK taught at some point in
your curriculum?
Yes
No
Which best describes how most of the applied/
clinical PK material is taught?
Standalone course(s)
Integrated or part of other courses
What textbook(s) do you use for this course?
Applied Biopharmaceutics and
Pharmacokinetics (Shargel)
Basic Clinical Pharmacokinetics (Winter)
Applied Clinical Pharmacokinetics (Bauer)
Aptied Pharmacokinetics and
Pharmacodynamics: Principles of
Therapeutic Drug Monitoring (Burton)
No textbook used
Yes
No

In which professional year(s) is applied/clinical PK taught?

1 st

2nd

3rd

4th

Approximately what percent of the material involves math, math models, equations, etc? $0-9$

$10-19$

20-29

30-39

40-49

$50-59$

60-69

$70-79$

80-89

90-100

Approximately what percent of the material is for clinical (non-math) discussion of kinetics and therapeutic drug monitoring?

$0-9$

$10-19$

20-29
48 (59)

24 (30)

20 (25)

3 (4)

21 (26)

32 (40)

$6(7)$

$75(93)$

$14(17)$

55 (68)

43 (53)

6 (7)

0

4 (5)

9 (11)

$12(15)$

22 (27)

12 (15)

14 (17)

4 (5)

1 (1)

Table 1. (Continued)

\begin{tabular}{lc}
\hline & $\mathbf{N}(\mathbf{\%})$ \\
\hline $30-39$ & $23(28)$ \\
$40-49$ & $15(19)$ \\
$50-59$ & $14(17)$ \\
$60-69$ & $8(10)$ \\
$70-79$ & $5(6)$ \\
$80-89$ & 0 \\
$90-100$ & 0 \\
Is pharmacogenomics taught in a standalone & \\
course? & \\
Yes & $36(44)$ \\
No & $45(56)$ \\
\hline Abbreviations: PK=pharmacokinetics
\end{tabular}

Abbreviations: $\mathrm{PK}=$ pharmacokinetics

advanced calculators. Lectures (95\%) and actual PK cases $(85 \%)$ were the main instructional methods used, and $58 \%$ included practice quizzes or examinations that counted for no credit. Guest lectures, assigned readings, and group assignments were also often used. One notable method of assessment was the use of audience response technology (41\%). Table 3 lists examples of how instructors structured their recitation classes. Many commented on the use of patient cases and assignments involving group activities.

Table 4 shows the specific course content such as various units of instructions and mathematical models, including dosing in special populations and certain disease states. Aminoglycosides, digoxin, and vancomycin were taught by at least $70 \%$ of respondents, as were dosing in renal dysfunction, hepatic dysfunction, children, critically ill, and obese. Amiodarone, heparin, lidocaine, methotrexate, order writing, procainamide, quinidine, and toxicokinetics were taught at fewer than $30 \%$ of responding institutions. Table 5 lists additional teaching methods provided by instructors, if applicable to their institution. Seventyseven percent of instructors asked to receive preliminary results of the survey.

Table 6 compares results from this study with those from Spruill and colleagues' 2003 study, highlighting the notable similarities and differences between them. Some significant differences were that the current study revealed that a larger portion of clinical PK was being integrated throughout the curriculum and there was a decrease in the instruction for certain medications such as procainamide, theophylline, and phenytoin.

\section{DISCUSSION}

Determining the structure of clinical PK within the curriculum was one research question that might have changed significantly since the previously published data 


\section{American Journal of Pharmaceutical Education 2018; 82 (9) Article 6430.}

Table 2. Methods of Instruction and Assessment of Clinical PK $(\mathrm{N}=82)$

\begin{tabular}{|c|c|}
\hline & $\mathbf{N}(\%)$ \\
\hline \multicolumn{2}{|l|}{$\begin{array}{l}\text { Which assessments are used to determine the } \\
\text { students' grades? }\end{array}$} \\
\hline Examinations & $79(98)$ \\
\hline Quizzes & $63(78)$ \\
\hline Class Participation & $26(32)$ \\
\hline Individual Assignments & $45(56)$ \\
\hline Group Assignments & $31(38)$ \\
\hline Other & $6(7)$ \\
\hline \multicolumn{2}{|l|}{$\begin{array}{l}\text { What instructional methods are used } \\
\text { in the course }(\mathrm{s}) \text { ? }\end{array}$} \\
\hline Lecture & $77(95)$ \\
\hline Guest lectures & $26(32)$ \\
\hline Assigned readings from primary literature & $33(41)$ \\
\hline $\begin{array}{l}\text { Audience response technology } \\
\text { ("clickers" or app) }\end{array}$ & $33(41)$ \\
\hline Laboratories & $22(27)$ \\
\hline Web-based programs & $9(11)$ \\
\hline Instructional videos & $14(17)$ \\
\hline Actual PK patient cases & $69(85)$ \\
\hline Projects & $10(12)$ \\
\hline Group assignments & $33(41)$ \\
\hline Recitation classes & $22(27)$ \\
\hline Practice quizzes/examinations (for no credit) & $47(58)$ \\
\hline Other & $15(19)$ \\
\hline \multicolumn{2}{|l|}{$\begin{array}{l}\text { For examinations, do students have to } \\
\text { memorize equations or are they provided? }\end{array}$} \\
\hline Memorize & $13(16)$ \\
\hline Provided & $68(84)$ \\
\hline Other & 0 \\
\hline \multicolumn{2}{|l|}{$\begin{array}{l}\text { For examinations, what is the most } \\
\text { complex type of calculator students are } \\
\text { permitted to use? }\end{array}$} \\
\hline Scientific calculator & $71(88)$ \\
\hline Graphing/programmable calculator & $10(12)$ \\
\hline
\end{tabular}

Abbreviations: $\mathrm{PK}=$ pharmacokinetics

as many programs have likely altered their curricula since 2003. However, it was not predicted that only $54 \%$ and $66 \%$ of respondents, respectively, would state that biopharmaceutics and basic PK was taught before clinical PK to lay the basic principles for the clinical material. Although this was higher than reported in the 2003 study, the authors of the current study did not predict that these prerequisites were not universally taught. ${ }^{3}$

One significant change from the 2003 study was the percentage of institutions that taught clinical PK as a standalone course vs those that have it integrated throughout the other courses. In 2003, 97\% of clinical PK was taught in a standalone course, whereas our research found that only $59 \%$ of respondents had a standalone course and $41 \%$ taught the material throughout the
Table 3. Summary of Comments Describing Clinical PK Recitation Classes

Open-ended responses to patient cases (math and theory/ application)

Individual or group assignments with application of concepts to case studies

Evaluating primary literature

Students bringing questions to class

Two-hour recitation for P1 year, PK only (1-credit class)

Workshops for small groups of students

Feedback from examinations and case studies

Instructors working with students to explain specific patient populations or unique dosing considerations

Abbreviations: $\mathrm{P} 1=$ first professional year; $\mathrm{PK}=$ pharmacokinetics

curriculum $(p<.01) .^{3}$ If executed properly, teaching clinical PK concepts throughout other therapeutic courses may create more significant learning experiences. As described by Fink, ${ }^{7}$ significant learning is less likely to occur as a single effort, but more likely as a result of an interactive dynamic among different types of learning. The development of foundational knowledge, application of skills and critical thinking, and integration of concepts are consistent with the interactive and interrelated nature of significant learning. Learning one clinical PK concept can enhance other types of learning such as caring and the human dimension, and these can enhance student learning about clinical PK. This interrelation can occur, for example, across specific clinical PK topics, through disease state management, or even across realms of life such as school and work. The shift to integrate clinical PK throughout the curricula is consistent with Fink's significant learning paradigm. ${ }^{7}$

The use of three clinical PK textbooks (Shargel, Winter, Bauer) accounted for $80 \%$ of respondents' answers, which is a change from the 2003 study that had a more diverse spread of resources used. ${ }^{4-6}$ Forty percent of respondents also reported using "other" textbooks, suggesting that multiple textbooks may be used within the same institution. Respondents were asked if they used a separate case-based book, 97\% of whom said, "no," making it unclear what other textbooks make up this large "other" category.

Respondents were asked to estimate what portion of their clinical PK material was taught using mathematical models and equations compared to more strictly clinical discussion (non-math). The portion of respondents that use mathematical models was comparable to the 2003 study. The 2003 study found that $66 \%$ of respondents reported between $30 \%$ and $69 \%$ of their material was math-based, compared to $68 \%$ of the current study's respondents. Seventy-nine percent of the respondents reported that 


\section{American Journal of Pharmaceutical Education 2018; 82 (9) Article 6430.}

Table 4. Course Content and Number and Percentage of Responding Institutions

\begin{tabular}{|c|c|}
\hline & $\mathbf{N}(\%)$ \\
\hline Aminoglycosides & $78(96)$ \\
\hline Aminoglycosides-once daily dosing & $68(84)$ \\
\hline Aminoglycosides-traditional dosing & $66(81)$ \\
\hline Amiodarone & $18(22)$ \\
\hline Carbamazepine & $52(64)$ \\
\hline Clinical consult writing & $25(31)$ \\
\hline Cyclosporine & $38(47)$ \\
\hline Dialysis & $52(64)$ \\
\hline Digoxin & $57(70)$ \\
\hline Dosing in hepatic dysfunction & $59(73)$ \\
\hline Dosing in renal dysfunction & $71(88)$ \\
\hline Heparin & $23(28)$ \\
\hline Hepatic elimination & $50(62)$ \\
\hline Lidocaine & $19(23)$ \\
\hline Lithium & $41(51)$ \\
\hline Methotrexate & $15(19)$ \\
\hline Order writing & $16(20)$ \\
\hline Pharmacodynamic principles of antibiotics & $53(65)$ \\
\hline Pharmacogenomics & $43(53)$ \\
\hline Phenobarbital & $52(64)$ \\
\hline Phenytoin & $29(36)$ \\
\hline PK in children & $58(72)$ \\
\hline PK in critically ill & $59(73)$ \\
\hline $\mathrm{PK}$ in geriatrics & $28(35)$ \\
\hline PK in obesity & $74(91)$ \\
\hline Procainamide & $16(20)$ \\
\hline Quinidine & $13(16)$ \\
\hline Tacrolimus & $33(41)$ \\
\hline Theophylline & $35(43)$ \\
\hline Toxicokinetics & $18(22)$ \\
\hline Valproic acid & $48(59)$ \\
\hline Vancomycin & $76(94)$ \\
\hline $\begin{array}{l}\text { Vancomycin-equation method (one } \\
\text { compartment model-first order kinetics) }\end{array}$ & $65(80)$ \\
\hline Vancomycin-Matzke method & $34(42)$ \\
\hline Warfarin & $43(53)$ \\
\hline
\end{tabular}

Abbreviations: $\mathrm{PK}=$ pharmacokinetics

non-math material made up $20 \%$ to $59 \%$ of the material whereas $63 \%$ of 2003 respondents answered in this range, a significant increase $(p<.05) .^{3}$

One item that was added to this survey was questioning the use of pharmacogenomics. Forty-four percent of respondents stated their curriculum contained a standalone pharmacogenomics course and $53 \%$ of respondents identified it as a unit of instruction related to clinical PK. In the 2003 study, pharmacogenomics was only briefly mentioned and was not quantified. ${ }^{3}$ This is not surprising due to the rapid development in pharmacogenomics in the past 20 years.

Compared to the 2003 study, this current study found that $41 \%$ of respondents used audience response
Table 5. Additional Teaching Methods Mentioned

\begin{tabular}{l}
\hline Individual or group presentations of patient cases and \\
recommendations \\
Writing a consultation, progress or SOAP note \\
Team-based learning \\
Computer-based PK simulations \\
Therapeutic drug monitoring notes \\
Pre-class videos followed up in-class quizzes on those videos \\
Active learning exercises/debates \\
Low-stake quizzes after every class via ExamSoft, \\
Blackboard, or on paper \\
Clinical vignettes of actual patient cases throughout the \\
semester \\
Homework assignments (problem sets and clinical \\
application) with feedback from instructor \\
Literature review applying PK concepts to a recent publication \\
\hline Abbreviations: SOAP=subjective, objective, assessment, plan; \\
PK=pharmacokinetics
\end{tabular}

technology and 58\% used practice examinations or quizzes for no credit. The authors suspect that both practices are newly implemented since the 2003 survey because of the ubiquitous nature of technology in the classroom and the evolving culture of audience engagement and evidence for active learning. ${ }^{8}$ Recitation classes were also sometimes used with examples of descriptions listed in Table 3.

There were some changes in units of instruction since the 2003 study but the most common medications remained to be aminoglycosides (96\%), digoxin (70\%), and vancomycin (94\%) and no statistical difference was found. ${ }^{3}$ All medications were taught at similar frequencies as the 2003 study that didn't find any statistical difference but with the following notable exceptions: procainamide, theophylline, and phenytoin decreased prevalence from $45 \%$ to $20 \%, 72 \%$ to $43 \%$, and $74 \%$ to $36 \%$, respectively ( $p<.01$ for all comparisons). ${ }^{3}$ This may be due to the decreased clinical utility of these medications. Warfarin and phenobarbital were the only two medications that were more frequently taught recently, increasing from $29 \%$ to $53 \%$ and from $45 \%$ to $64 \%$ of respondents, respectively ( $p<.05$ for all both). ${ }^{3}$

One of the strengths of this study was the measures to identify and reach the single best person to provide information about their institution's clinical PK delivery. The initial email to the deans and chairpersons contained sample questions from the survey to show what data this study was trying to collect. In the introduction to the survey, descriptions of "basic" and "clinical" PK were included and the authors restated that they were trying to reach the person who could speak on behalf of the instruction of the latter material. However, based on differences in 


\section{American Journal of Pharmaceutical Education 2018; 82 (9) Article 6430.}

Table 6. Summary Comparison of Curricular Position and Clinical PK Course Content

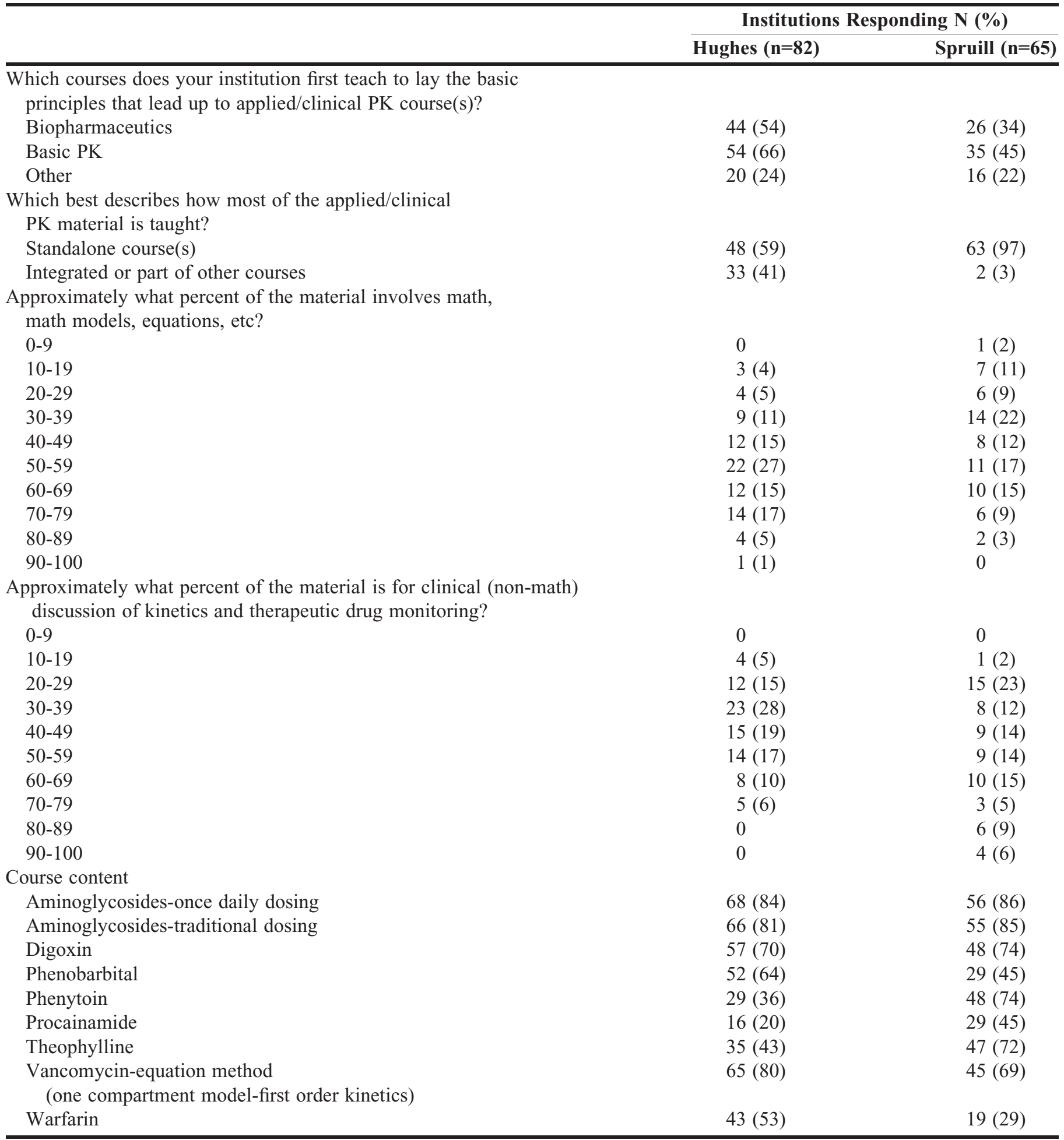

Abbreviations: $\mathrm{PK}=$ pharmacokinetics

curricular design (ie, standalone course vs integrated throughout other courses), some institutions had difficulty identifying the best person to answer the survey. Other strengths were the high response rate $(76 \%)$ and the assurances taken to ensure only one survey was completed per institution. Once the ideal survey respondent was identified and contacted by the study authors, it was very common for them to be enthusiastic about this research. During survey collection, it was noted that these lead faculty often expressed interest in learning the results prior to publication, and at least 


\section{American Journal of Pharmaceutical Education 2018; 82 (9) Article 6430.}

one offered to get involved in future research involving pedagogy in clinical PK.

The main limitations of this study were those typically associated with survey methodology such as difficulty with recall and the general subjective nature of some of the data. The study authors spoke to potential respondents who stated that there was no single person who would be able to answer this survey because of the distribution of all clinical PK content throughout their curriculum and that communication among these faculty members was not formalized. This led to at least one potential respondent to not participate in the survey.

\section{CONCLUSION}

There have been some changes to the delivery of clinical PK in the past decade. This study describes how clinical PK is situated in the curricula, what the common delivery and assessment methods are, and what units of instructions are currently being taught. A move toward spreading clinical PK throughout the curriculum while maintaining the math-centric nature of the material has also occurred. The most commonly studied medications (ie, aminoglycosides, digoxin, vancomycin) have not significantly changed but less prescribed medications (ie, procainamide, theophylline, phenytoin) are taught significantly less. Common PK principles include renal and hepatic dosing, pediatrics, critically ill, obesity, and pharmacodynamics of antibiotics.

\section{REFERENCES}

1. Accreditation Council for Pharmacy Education. Accreditation standards and key elements for the professional program in pharmacy leading to the doctor of pharmacy degree. Standards 2016. https:// www.acpeaccredit.org/pdf/Standards2016FINAL.pdf. Accessed March 14, 2017.

2. Pharmacokinetics and Anticoagulation Service. University of Kentucky HealthCare Pharmacy Services. 2017. https://ukhealthcare. uky.edu/pharmacy-services/professionals/pharmacokineticsanticoagulation-service/. Accessed November 2, 2018.

3. Spruill WJ, Wade WE. Curricular and content survey of clinical pharmacokinetics courses. Am J Pharm Educ. 2003;67(2):Article 47. 4. Shargel L, Yu ABC. Applied Biopharmaceutics and Pharmacokinetics. $3^{\text {rd }}$ ed. Stanford, CT: Appleton and Lange; 1999. 5. Winter ME. Basic Clinical Pharmacokinetics. $3^{\text {rd }}$ ed. Vancouver, WA: Applied Therapeutics, Inc.; 1994.

6. Bauer LA. Applied Clinical Pharmacokinetics. New York, NY: McGraw-Hill; 2001.

7. Fink LD. Creating Significant Learning Experiences. An Integrated Approach to Designing College Courses. San Francisco, CA: Jossey-Bass; 2003.

8. Freeman S, Eddy SL, McDonough M, et al. Active learning increases student performance in science, engineering, and mathematics. Proc Natl Acad Sci USA. 2014;111(23):8410-8415. 9. Burton ME. Applied Pharmacokinetics \& Pharmacodynamics, Principles of Therapeutic Drug Monitoring. $4^{\text {th }}$ ed. Baltimore, MD: Lippincott Williams \& Wilkins; 2006. 